\title{
INTERAKSI ENERGETIK GURU DAN SISWA PADA PEMBELAJARAN ABAD 2 I
}

\author{
Energetic Interaction of Teachers and Students on $2 I^{\text {st }}$ Century Learning
}

\author{
Ady Ferdian Noor ${ }^{1,2 *}$ \\ Muhammad Nur Wangid ${ }^{2}$
}

Universitas Muhammadiyah Palangkaraya, Palangka Raya, Central Kalimantan, Indonesia

2Universitas Negeri Yogyakarta, Yogyakarta, DI Yogyakarta, Indonesia

*email:

adyferdian.2018@student.uny.ac.id

Kata Kunci:
Energetik
Interaksi
Pembelajaran Abad 2I
Keywords:
Energetic
Interaction
2 Ist Century Learning

Accepted

February 2019

Published

June 2019

\begin{abstract}
Abstrak
Pembelajaran memerlukan interaksi, Interaksi adalah suatu jenis tindakan yang terjadi ketika dua atau lebih objek mempengaruhi atau memiliki efek satu sama lain. Pembelajaran melalui interaksi yang kurang energetik dapat menyebabkan ketidakseimbangan transfer pembelajaran. Tendensi yang muncul adalah siswa akan banyak mengetahui banyak tentang sesuatu, namun menjadi kurang memiliki sistem nilai, sikap, minat maupun apresiasi secara positif terhadap apa yang diketahui. Siswa akan melakukan praktik pelanggaran misalnya senang berkelahi sesama teman, kurang menghargai orang lain, dan kurang mempunyai sopan santun. Atmosfer akademik di sekolah dasar untuk siswa dapat belajar efektif adalah kondisi dimana siswa dapat berkolaborasi, bekerjasama, berkomunikasi dengan menggunakan interaksi segala arah tidak ada rasa takut dan merasa malah dilindungi serta mereka merasa diperlakukan secara adil tidak pandang suku, agama, ras, antar golongan, dan gender sehingga mencapai tujuan yang diinginkan baik tujuan pendidikan nasional maupun tujuan sekolah dasar. Tujuan penelitian ini untuk mendeskripsikan interaksi energetik guru dan siswa di sekolah pada pembelajaran abad 21. Untuk mencapai tujuan penelitian, Penelitian ini menggunakan metode penelitian perpustakaan dan dokumenter. Interaksi energetik guru dan siswa harus dilandasi hubungan yang baik terlebih dahulu antara guru dan siswa artinya siswa merasa guru adalah orangtua dan temannya yang dapat diajak berinteraksi tanpa rasa takut tetapi tetap menghormati. Interaksi tanpa rasa takut tetapi tetap menghormati diperlukan karena sesuai dengan salah satu keterampilan pembelajaran abad 21 yaitu kolaborasi. Kolaborasi yang baik menyebabkan pembelajaran menjadi menyenangkan sehingga pembelajaran menjadi efektif.
\end{abstract}

(C) 2019 The Authors. Published by Institute for Research and Community Services Universitas Muhammadiyah Palangkaraya. This is Open Access article under the CC-BY-SA License (http://creativecommons.org/licenses/by-sa/4.0/). DOI: https://doi.org/10.33084/anterior.v18i2.456.

\section{PENDAHULUAN}

Pembelajaran memerlukan interaksi yang baik antara guru dan siswa. Tedjoworo (2018) mengemukakan Pembelajaran sebenarnya ialah proses pengenalan dan penerimaan kontekstualitas kita, dimanapun kita berada. Masruhani (2016) mengemukakan interaksi merupakan proses pengiriman dan penerimaan informasi antara individu dengan kelompok, individu dengan individu atau 
kelompok dengan kelompok yang didasarkan pada adanya pesan yang akan disampaikan. Atmosfer akademik yang memungkinkan siswa sekolah dasar untuk belajar efektif dimulai dari landasan dasar pemikiran berdasarkan Pembukaan UUD NRI Tahun 1945 yaitu mencerdaskan kehidupan bangsa diimplementasikan pada UU Nomor 20 Tahun 2003 tentang Sistem Pendidikan Nasional BAB II Pasal 3 yaitu tujuan pendidikan nasional untuk berkembangnya potensi peserta didik agar menjadi manusia yang beriman dan bertakwa kepada Tuhan Yang Maha Esa, berakhlak mulia, sehat, berilmu, cakap, kreatif, mandiri, dan menjadi warga negara yang demokratis serta bertanggung jawab mencerdaskan kehidupan bangsa melalui pengembangan potensi siswa di sekolah dasar.

Sekolah merupakan tempat untuk belajar bagi siswa baik memperoleh teori maupun pengalaman belajar. Sekolah dikelola oleh pelaku-pelaku mulai dari kepala sekolah, guru, siswa, dan komite (Suyati, 2016). Atmosfer akademik di sekolah dasar untuk siswa dapat belajar efektif adalah kondisi dimana siswa dapat berkolaborasi, bekerjasama, berkomunikasi dengan menggunakan segala arah tidak ada rasa takut dan merasa malah dilindungi serta mereka merasa diperlakukan secara adil tidak pandang suku, agama, ras, antar golongan, dan gender sehingga mencapai tujuan yang diinginkan baik tujuan pendidikan nasional maupun tujuan sekolah dasar (Widodo, 2016). Pihak sekolah jangan melupakan ekologi sekolah dasar itu sendiri baik dari sisi toilet, tempat pembuangan sampah, penghijauan, dan selokan sekolah harus ditata rapi, teratur, bersih, indah, dan tertib sehingga selain ruang sekolah yang nyaman dan sesuai dengan jumlah siswa juga sarana pembelajaran seperti meja dan kursi dapat bergerak artinya ruang sesuai perbandingan dengan peraturan terkait. Siswa dapat belajar efektif sehingga mampu menampilkan potensi dirinya yang terpendam sesuai bakat dan minat dalam dirinya bukan berasal dari kemauan guru dan orang lain dan itu yang memastikan adalah komite sekolah (Riyanta, 2016).
Salah satu ciri abad ke-2I adalah meningkatnya interaksi warga dunia secara langsung maupun tidak langsung yang ditopang oleh kemajuan Teknologi Informasi dan Komunikasi (Sukmana, 2018). Zaman selalu terus berkembang mengikuti perkembangan teknologi, yang pada saat ini sudah memasuki era industri 4.0. Pemanfaatan berbagai aktifitas pembelajaran yang mendukung industri 4.0 merupakan keharusan dengan model resource sharing dengan siapapun dan dimanapun, pembelajaran kelas dan laboratorium dengan augmented (pengalaman interaktif dari lingkungan dunia nyata di mana benda-benda yang berada di dunia nyata "ditambah" oleh informasi persepsi yang dihasilkan komputer) dengan bahan virtual, bersifat interaktif, menantang, serta pembelajaran yang kaya isi bukan sekedar lengkap (Triyono, 2017). Artinya siswa dapat mengembangkan kemampuan menguasai pengetahuan dan teknologi (lbrahim, 2012). Fenomena pembelajaran abad 2I menunjukkan bahwa agar siswa mampu menulis monolog "aspect of love" dalam bentuk puisi, guru meminta siswanya secara individu membuka http://iearn.org. Siswa kemudian diminta untuk memilih salah satu proyek membuat puisi terkait dengan "aspek kasih sayang" tersebut dan mengikuti prosedur yang disarankan. Siswa menulis puisi secara kreatif dalam bentuk MS Word atau MS Powerpoint. Siswa merekam pembacaan puisi masing-masing menggunakan handphone. Kemudian mengirimkan puisinya dan video ke http://iearn.org dan kanal youtube untuk mendapatkan umpan balik dari siswa lain di seluruh dunia. Hasil kerja, plus umpan balik dari siswa lain di seluruh dunia dijadikan sebagai portfolio siswa tersebut sebagai salah satu bahan penilaian oleh guru tersebut. Pembelajaran memerlukan kolaborasi yang didukung dengan teknologi (Anggraini et al., 2015; Rahmaniati \& Supramono, 2015).

Dalam teori Sosiologi istilah interaksi terkait dengan tingkatan individu. Damsar (20/5) mengemukakan analisis tingkatan individu memiliki keragaman tantang 
fokus perhatian, konsep masyarakat, individu, dan akar pemikiran. Tingkatan individu terdiri dari paling tidak tiga bentuk analisis, yaitu analisis pemaknaan sosial, analisis pengetahuan, dan analisis pertukaran sosial. Analisis pemaknaan sosial memosisikan manusia sebagai makhluk yang aktif kreatif dalam penciptaan dunia mereka. Manusia menciptakan simbol, yang dengannya manusia berinteraksi, misalnya guru menggunakan simbol untuk membelajarkan siswa tentang pengetahuan.

Analisis pengetahuan menitikberatkan penjelasannya pada kenyataan kehidupan sehari-hari, dimana kesadaran, proses kognitif dan praktik sehari-hari yang dilakukan oleh siswa dan guru dalam menjalani pembelajaran di sekolah diawasi oleh kepala sekolah. Manusia merupakan insan kreatif sejauh dalam menggunakan stock of knowledge-nya. Analisis pertukaran menempatkan manusia sebagai makhluk yang rasional, selalu mempertimbangkan untung rugi. Oleh karena itu, manusia dipandang tergantung pada persoalan untung rugi dalam hubungan sosialnya. Guru dan siswa saling memperlakukan diri mereka dalam hubungan untung rugi artinya guru memberikan pembelajaran kepada siswa agar mampu mengembangkan potensi dirinya, siswa belajar dengan efektif maka guru menjadi guru yang berhasil mengajar dan mendidik (Rehalat, 20I4).

Pembelajaran melalui interaksi yang kurang energetik dapat menyebabkan ketidakseimbangan transfer pembelajaran. Zubaedi (2009) mengemukakan tendensi yang muncul adalah peserta didik akan banyak mengetahui banyak tentang sesuatu, namun menjadi kurang memiliki sistem nilai, sikap, minat maupun apresiasi secara positif terhadap apa yang diketahui. Anak akan mengalami perkembangan intelektual tidak seimbang dengan kematangan kepribadian sehingga melahirkan sosok spesialis yang kurang peduli dengan lingkungan sekitarnya dan rentan mengalami distorsi nilai. Siswa akan melakukan praktik pelanggaran misalnya senang berkelahi sesama teman, kurang menghargai orang lain, dan kurang mempunyai sopan santun. Suyanto dan Jihad (2013) mengemukakan untuk memotivasi belajar siswa, guru harus selalu inovatif dalam mengadopsi metode-metode terbaru dalam pembelajaran dan menempatkan siswa sebagai pusat pembelajaran. Sejauh mana materi disampaikan bukan tergantung pada guru dan kurikulumnya, tetapi bergantung pada kesiapan belajar siswa. Kreativitas siswa dibangun melalui berbagai aktivitas diskusi kelompok, diskusi panel, kunjungan lapangan, permainan peran, dan permainan tradisional. Albert Einstein, "It is the supreme art of the teacher to awaken joy in creative expression and knowledge" (Seni tertinggi pada seseorang guru adalah kemampuan membangkitkan kegembiraan dengan pengetahuan dan ekspresi yang kreatif).

Kemampuan membangkitkan kegembiraan dengan pengetahuan dan ekspresi yang kreatif harus dilandasi dengan sistem-sistem formal sehingga guru mampu menghasil metode dan model pembelajaran yang inovatif. Pendekatan sistem-sistem formal dapat menghasilkan situasi dan kondisi yang akrab sehingga tranfers konten dapat sesuai dengan tujuan pembelajaran (Prasetyo, 2007). Butler mengemukakan pendekatan sistem-sistem formal dikaitkan dengan filosofi pendidikan yaitu: I. Guru adalah pencipta lingkungan pendidikan siswa dan merupakan sumber ilham baginya; 2 . Sebuah cara yang penting dan berharga di mana tanggapan siswa dilahirkan adalah melalui kegiatan yang bersifat meniru (imitatif), khususnya jika diarahkan oleh para panutan dalam hal karya kreatif serta kepribadian guru yang budiman; 3. Batu pijakan lain ke arah tanggapan siswa adalah ketertarikan. Lebih baik jika ketertarikan menjadi dasar sebagaian besar kegiatan siswa. Ketertarikan harus diimbangi dengan kerja keras yang didukung penekanan disiplin dari luar diri siswa; 4. Tindakan guru yang efektif yaitu menghasilkan tanggapan aktif dari siswa; 5. Buku-buku ajar dan mata pelajaran pun harus mencakup kaitan pengalaman langsung dengan aktualisasi (Susilo, 2016). Guru harus 
menerapkan model pembelajaran "Problem-basedLearning". Problem based Learning is a student-centered approach that organizes curriculum and instruction around carefully crafted "ill-structured" and real-world problem situations. (Arends \& Kilcher, 2010). Metodametoda pembelajaran harus inovatif sehingga menciptakan perasaan tegang (suspense) dalam diri siswa, perasaan tegang itu dapat dipecahkan melalui usaha aktif siswa itu sendiri (Kholisotin \& Lastaria, 2017; O’Neil, 198I).

Usaha aktif siswa diupayakan semaksimal mungkin mampu menjalin interaksi yang baik. Interaksi menghasilkan kolaborasi dan kerjasama yang sempurna karena mereka dapat berdiskusi memecahkan berbagai permasalahan yang terjadi baik permasalahan kelompok maupun permasalahan pelajaran. Sahlberg (201I) mengemukakan hal di masa depan dibutuhkan orang, tetapi kecil kemungkinannya dipelajari di mana pun juga, adalah pemecahan masalah nyata dengan bekerjasama dengan orang lain. Ini akan menjadi satu dari fungsifungsi dasar sekolah masa depan; mengajarkan kerjasama dan pemecahan masalah dalam kelompok kecil dengan orang-orang yang heterogen. Tedjoworo (2018) mengemukakan pembelajaran di abad ini tidak bisa dibiarkan terlalu teknis dan teknologis. Kita perlu menahan diri dalam hal teknologi dan inovasi. Kembali pada yang humanum. Pembelajaran mesti dilakukan dengan bercakap-cakap secara langsung (interaksi), di dalam kebersamaan yang relasional dan inderawi, serta melibatkan semakin banyak orang maupun sudut pandang. Tujuan penelitian ini untuk mendeskripsikan interaksi energetik guru dan siswa di sekolah pada pembelajaran abad 21 .

\section{METODOLOGI}

Penelitian ini menggunakan metode penelitian perpustakaan dan dokumenter. Darmadi (2014) mengemukakan bahwa penelitian ini merupakan suatu bentuk penelitian yang menggunakan berbagai literatur sebagai salah satu dokumen. Kepustakaan mempunyai peran sangat penting dalam suatu penelitian. Kajian pustaka merupakan bagian penting dalam sebuah penelitian yang kita lakukan. Kajian pustaka disebut juga kajian literatur, atau literature review (Setyosari, 20I5). Penelitian ini mencoba mengkaji dari jurnal-jurnal ilmiah dan buku teks baik secara fisik maupun e-journal maupun e-books terkait tentang interaksi energetik pembelajaran yang dilakukan oleh guru dan siswa pada pembelajaran abad 21 .

\section{HASIL DAN PEMBAHASAN}

Sekolah adalah tempat belajar dan pembelajaran. Siswa belajar melalui teori dan pengalaman yang ditanamkan oleh guru. Siswa belajar tentang pengetahuan, sikap, dan keterampilan secara keseluruhan dan seimbang. Guru menciptakan pembelajaran yang kreatif dan inovatif berdasarkan pada metode dan model pembelajaran abad 2I. Sekolah adalah tempat bergaul antar sesama siswa, dengan guru, dengan kepala sekolah secara harmonis dan dinamis tanpa membeda-bedakan satu dengan lainnya. Sekolah dibangun dalam landasan pendidikan humanis sesuai dengan prinsip-prinsip pendidikan yang humanis (Prasetiawati, 2017). Pemikiran yang dikembangkan oleh $\mathrm{Ki}$ Hadjar Dewantara bahwa mendidik adalah proses memanusiakan manusia (humanisasi). Suyanto dan Jihad (2013) mengemukakan Sekolah akan menjadi platform yang tepat untuk memenuhi tujuan pendidikan jika hubungan antara siswa dan guru dipelihara dengan baik. Guru adalah teman, filsuf, dan sosok panduan bagi siswa. Seorang guru adalah motivator terbaik, seorang pecinta dan pengisi kekuatan. Siswa terinspirasi oleh guru sebagai pemimpin. Sahlberg (20II) mengemukakan Otoritas dan kebanyakan orangtua mengerti bahwa mengajar, mengasuh, dan mendidik anak-anak adalah proses yang terlalu kompleks untuk diukur secara kuantitatif. Di sekolah-sekolah Finlandia, prinsip operasinya adalah kualitas guru dan sekolah ditentukan 
melalui interaksi timbal balik antara sekolah dan siswasiswa, bersama orangtua mereka.

Interaksi timbal balik menghasilkan perubahan pada perkembangan fisik dan psikologis anak. Sahlberg (20I I) mengemukakan komponen perubahan pendidikan yang menciptakan gagasan dan inovasi baru mestilah memberikan cukup dorongan dan dukungan untuk pengambilan resiko yang akan memungkinkan kreativitas tumbuh subur di ruang-ruang kelas dan sekolah. Fernanda et al. (20I2) menyatakan manusia tidak pernah statis. Semenjak pembuahan hingga ajal selalu terjadi perubahan, baik dalam kemampuan fisik maupun kemampuan psikologis. Interaksi dalam pembelajaran dapat terjadi energetik atau tidak tergantung komunikasi timbal balik guru-siswa.

\section{KESIMPULAN}

Interaksi energetik guru dan siswa di sekolah harus dilandasi hubungan yang baik terlebih dahulu antara guru dan siswa artinya siswa merasa guru adalah orangtua dan temannya yang dapat diajak berinteraksi tanpa rasa takut tetapi tetap menghormati. Interaksi tanpa rasa takut tetapi tetap menghormati diperlukan karena sesuai dengan salah satu keterampilan pembelajaran abad 21 yaitu kolaborasi. Kolaborasi yang baik menyebabkan pembelajaran menjadi menyenangkan sehingga pembelajaran menjadi efektif. Pembelajaran yang efektif akan mencapai tujuan pembelajaran dari guru dan sekolah. Keterbatasan penelitian ini yaitu hanya meneliti interaksi energetik guru dan siswa belum menyentuh interaksi menggunakan media pembelajaran berbasis teknologi guru dan siswa. Pembahasan berikutnya dapat dilakukan dengan melibatkan media pembelajaran berbasis teknologi informasi komunikasi.

\section{REFERENSI}

Anggraini, W., Hudiono, B., \& Hamdan. 2015. Pemberian Umpan Balik (Feedback) terhadap Hasil Belajar dan Self-Efficacy Matematis Siswa
Kelas VII SMP. Jurnal Pendidikan dan Pembelajaran, 4, I-I3.

Arends, R.I. \& Kilcher, A. 2010. Teaching for Student Learning: Becoming an Accomplished Teacher. Newyork: Routledge. p. 326.

Damsar. 2015. Pengantar Teori Sosiologi. Jakarta: Kencana. p. 163.

Darmadi, H. 2014. Metode Penelitian Pendidikan dan Sosial: Teori Konsep Dasar dan Implementasi. Bandung: Alfabeta. p. 190.

Fernanda, M.M., Sano, A., \& Nurfarhanah. 2012. Hubungan antara Kemampuan Berinteraksi Sosial dengan Hasil Belajar. Konselor: Jurnal Ilmiah Konseling, I, I-7.

Ibrahim, M. 2012. Modul Hakikat Kurikulum dan Pembelajaran. Jakarta: UT Press.

Kholisotin, L., \& Lastaria, L. 2017. Fungsi Kesantunan Berbahasa dalam Interaksi Guru dan Murid di Lingkungan MIS Al Jihad Palangka Raya. Anterior Jurnal, 17, 52-59.

Masruhani, S.N. 2016. Pola Interaksi Guru dan Siswa pada Pendidikan Islam Klasik. Qathrunâ, 3, 143-160

O’Neil, W.F. 198I. Educational Ideologies: Contemporary Expressions of Educational Philosophies. California: Goodyear Publishing Company. Alih bahasa: Naomi, O.I. 2008. Ideologi-Ideologi Pendidikan. Yogyakarta: Pustaka Pelajar. pp. I4-I5.

Prasetiawati, E. 2017. Urgensi Pendidikan Multikultur untuk Menumbuhkan Nilai Toleransi Agama di Indonesia. Tapis: Jurnal Penelitian Ilmiah, I, 272-303.

Prasetyo, I. 2007. Peran Pamong Belajar Dalam Meningkatkan Motivasi Warga Belajar Program Paket B. Diklus: Jurna; Pendidikan Luar Sekolah, 6, 42-86.

Rahmaniati, R. \& Supramono, S. 20I5. Pembelajaran ISETS (Islamic, Science, Environment, Technology and Society) terhadap Hasil Belajar Siswa. Anterior Jurnal, I4, 194-200.

Rehalat, A. 2014. Model Pembelajaran Pemrosesan Informasi. Jurnal Pendidikan IImu Sosial, 23, III. 
Riyanta, T. 2016. Mengembangkan Budaya Mutu Sekolah melalui Kepemimpinan Transformasional. Jurnal Manajemen Pendidikan, 12, 37-48.

Setyosari, P. 2015. Metode Penelitian Pendidikan dan Pengembangan. Jakarta: Prenadamedia Group. p. II7.

Shalberg, P. 201I. Finnish Lessons: What Can the World Learn from Educational Change in Finland? Newyork: Teachers College Press. Alih bahasa: Muchlis, A. 2014. Finnish Lessons: Mengajar Lebih Sedikit, Belajar Lebih Banyak ala Finlandia. Bandung: Penerbit Kaifa. p. 292.

Sukmana, A. 2018. Mengembangkan Pembelajaran Abad ke-2I di Unpar. Majalah Parahyangan, 5, I415.

Susilo, S.V. 2016. Optimalisasi Kompetensi Guru dalam Membangun Indonesia Emas dalam Perspektif Pendekatan Sosial Budaya. In Proceeding of The International Seminar on Philosophy of Education, Universitas Pendidikan Indonesia, Bandung, 10 Desember 2016. pp. 81-87.

Suyanto \& Jihad, A. 2013. Menjadi Guru Profesional: Strategi meningkatkan Kualifikasi dan Kualitas Guru di Era Global. Jakarta: Erlangga. Pp. 98-99.

Suyati, E.S. 2016. Pengelolaan Manajemen Koperasi Sekolah. Pedagogik: Jurnal Pendidikan, II, 8896.

Tedjoworo, H. 2018. Pembelajaran Kultural: Berfilsafat dan Berteologi "Dari Bawah." Majalah Parahyangan, 5, 8-II.

Triyono, M.B. 2017. Tantangan Revolusi Industri 4.0 (i4.0) bagi Pendidikan Vokasi. In Proceeding Semnasvoktek, Denpasar Bali, 28 Oktober 2017. I-5.

Widodo, W. 2016. Wujud Kenyamanan Belajar Siswa, Pembelajaran Menyenangkan, dan Pembelajaran Bermakna di Sekolah Dasar. ArRisalah: Media Keislaman, Pendidikan dan Hukum Islam, I4, 22-37.

Zubaedi. 2009. Pendidikan Berbasis Masyarakat: Upaya Menawarkan Solusi terhadap Berbagai Problem Sosial. Yogyakarata: Pustaka Pelajar. p. 2-3. 